\title{
Characterization of a Nanofiltration Membrane Used for Demineralization of Underground Brackish Water by Application of Transport Equations
}

\author{
Ken-ich Ikeda $^{1)}$, Shoji Kimura ${ }^{2)}$ and Korekazu Ueyama ${ }^{3)}$ \\ 1) Nitto Denko Corp., 1-1-2 Shimohozumi, Ibaraki, Osaka 567-0041 \\ 2) Dept. of Environ. Chem. Eng., Kogakuin University, \\ 1-24-2 Nishi-Shinjuku, Shinjuku-ku, Tokyo 163-8677 \\ 3) Dept. of Chem. Eng., Osaka University, Machikaneyama, Toyonaka 560-8531
}

Our proposal is that over a certain range of the solute concentration of multi-component electrolyte mixtures, it is possible to assume that each ion can transport independently through a membrane without interaction between the ions and between each ion and the membrane charge. In this paper, the results of experiments obtained using a commercial nanofiltration membrane with 8 kinds of underground brackish water are reported ; the results are then used to obtain ion permeabilities using transport equations. From these results it is possible to estimate each ion concentration and $\mathrm{pH}$ in the permeate. The effect of osmotic pressure can be estimated from the calculated ion concentrations. Finally, it is shown that the mass transfer coefficients obtained can be correlated to the similar equation previously reported for the spiral-wound type module.

Although assumptions made in this paper have a certain limit in application, with this method it is simple to estimate permeate water qualities.

Key wards : nanofiltration/brackish water/ion permeability/reflection coefficient/spiral $\bmod -$ ule / mass transfer coefficient

\section{Introduction}

Many water softening plants, which have adopted the nanofiltration (NF) process, are now running in Florida, U.S.A. In Japan, NF membranes were tested as one of the alternative water purification processes for drinking water purification in the New Membrane Aqua Century 21 (MAC21) Project organized by the Ministry of Public Health and Welfare from 1994 to 1996.
In these applications, it is important to estimate the qualities of the permeated water through NF membranes, but the results of the characterization of NF membranes using transport equations have not been published. Although several papers have been published on mixed electrolyte permeation through membranes, they treated only two electrolyte mixtures ${ }^{1 \sim 7)}$. In this paper, we propose an analytical method based on basic transport equations and show that this 
Table 1 Solutes concentration of synthetic brackish water

\begin{tabular}{|c|c|c|c|c|c|c|c|c|c|c|}
\hline & \multirow{2}{*}{$\begin{array}{c}\text { molecular } \\
\text { weight }\end{array}$} & \multicolumn{8}{|c|}{ synthetic brackish water } & \multirow{2}{*}{ unit } \\
\hline & & model A & model B & $\operatorname{model} B / 2$ & model B/4 & model $\mathrm{B} / 8$ & S. CA model A & S. CA model B & IA model A & \\
\hline $\mathrm{Na}$ & 22.99 & 417.40 & 396.40 & 142.80 & 63.30 & 28.20 & 83.90 & 48.10 & 322.90 & \multirow{7}{*}{ (as lon) $\mathrm{mg} / \mathrm{l}$} \\
\hline $\mathrm{K}$ & 39.10 & 0.00 & 218.80 & 166.80 & 27.80 & 21.30 & 5.60 & 1.20 & 11.30 & \\
\hline $\mathrm{Ca}$ & 40.08 & 7.80 & 198.90 & 86.10 & 30.60 & 11.00 & 84.60 & 45.20 & 113.20 & \\
\hline $\mathrm{Mg}$ & 24.31 & 20.50 & 61.70 & 26.20 & 9.40 & 3.40 & 29.10 & 19.20 & 50.30 & \\
\hline $\mathrm{Cl}$ & 35.45 & 223.80 & 375.20 & 166.70 & 60.40 & 20.70 & 38.20 & 25.00 & 67.30 & \\
\hline $\mathrm{HCO}_{3}$ & 61.02 & 660.90 & 28.50 & 14.50 & 6.30 & 3.60 & 161.70 & 131.80 & 271.10 & \\
\hline $\mathrm{SO}_{4}$ & 96.06 & 142.80 & 1044.40 & 403.80 & 140.70 & 47.40 & 186.40 & 43.10 & 626.80 & \\
\hline $\mathrm{SiO}_{2}$ & 60.08 & 0.00 & 0.00 & 0.00 & 0.00 & 0.00 & 12.00 & 14.00 & 12.00 & $\left(\mathrm{as} \mathrm{SiO}_{2}\right) \mathrm{mg} / \mathrm{l}$ \\
\hline Total Hardness & & 103.60 & 750.20 & 322.70 & 115.00 & 41.40 & 330.80 & 191.70 & 489.20 & \multirow{2}{*}{$\left(\right.$ as $\mathrm{CaCO}_{3}$ ) $\mathrm{mg} / \mathrm{l}$} \\
\hline M-Alkalinity & & 541.90 & 23.40 & 11.90 & 5.20 & 3.00 & 132.60 & 108.10 & 222.30 & \\
\hline TDS & & 1473.00 & 2324.00 & 1006.90 & 338.50 & 135.60 & 601.50 & 327.60 & 1474.90 & $\mathrm{mg} / l$ \\
\hline Conductivity & & 1370.00 & 2880 & 1261 & 517 & 191 & 648 & 384 & 1435 & $\mu \mathrm{S} / \mathrm{cm}$ \\
\hline $\mathrm{pH}$ & & 8.80 & 7.40 & 6.91 & 6.70 & 6.40 & 8.20 & 7.90 & 8.20 & - \\
\hline Total Ion Conc. & & 37.82 & 52.26 & 22.85 & 7.89 & 3.32 & 12.97 & 7.59 & 32.29 & $\mathrm{mM} / l$ \\
\hline
\end{tabular}

S. CA ; Southern California, IA ; Iowa

method is useful for the prediction of multi-component ion concentrations in permeated water.

Our proposal is that over a certain range of solute concentrations of multi-component electrolyte mixtures, it is possible to assume that each ion can transport independently through a membrane without any interaction between the ions and between each ion and a membrane charge. If this principle can be adopted, it becomes very simple to estimate the permeate water qualities.

In this paper, we report the results of permeation experiments obtained using a $\mathrm{com}^{-}$ mercial nanofiltration membrane with 8 kinds of underground brackish water, and the results are used to obtain the permeabilities of each ion using transport equations. From these results it is shown that each ion concentration and $\mathrm{pH}$ in the permeate can be calculated and coincided well with experimental values. It is also shown that the effect of osmotic pressure on fluxes can be es- timated from calculated ion concentrations.

\section{Experimental}

The nanofiltration membrane used is a 2-inch element of the spiral wound type, $\mathrm{de}^{-}$ signated as NTR-739HF, manufactured by Nitto Denko Corp. The applied pressure is varied from 0.2 to $2 \mathrm{MPa}$, and the water re $^{-}$ covery ratio is varied from 3 to $70 \%$ by changing the feed flow velocity. There are 8 kinds of underground feed water used, that is, Model A, Model B, 2,4, and 8 times diluted water of Model B, Southern California brackish water A and B, and Iowa brackish water A. Their water qualities are summarized in Table 1. Analyzed concentrations of the permeates are $\mathrm{Na}^{+}, \mathrm{K}^{+}, \mathrm{Ca}^{2+}, \mathrm{Mg}^{2+}, \mathrm{Cl}^{-}$, $\mathrm{HCO}_{3}{ }^{-}, \mathrm{SO}_{4}{ }^{2-}$, $\mathrm{SiO}_{2}$, total hardness, M-alkalinity and TDS. Because analytical data thus obtained are too numerous, only the representative data will be reported. 


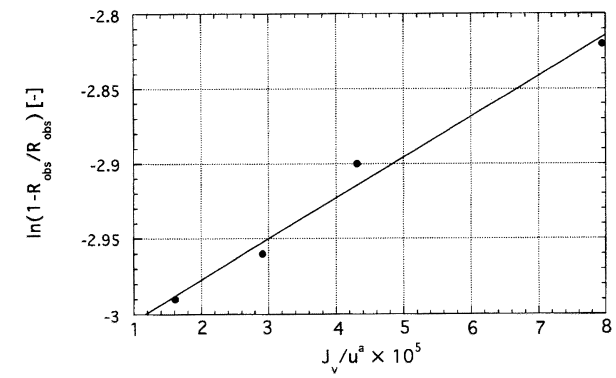

Fig. 1 The velocity variation method. (Estimation of $\mathrm{R}$ and $\mathrm{k}$ )

\section{Analytical}

\section{1 Analysis by transport equations}

To obtain transport coefficients from reverse osmosis experimental data, the following equation derived by Spiegler \& Kedem ${ }^{8)}$ is generally used, which gives a true rejection of a membrane, $R$, as

$$
R \equiv \frac{C_{M}-C_{P}}{C_{M}}=\frac{\sigma \cdot(1-F)}{(1-\sigma \cdot F)^{\prime}}
$$

where $\mathrm{F}$ is given as

$$
F=\exp \left[-\frac{J_{V}(1-\sigma)}{P}\right]
$$

$\mathrm{P}$ and $\sigma$ are the solute permeability and the reflection coefficient, respectively. The concentration at a membrane surface, $\mathrm{C}_{M}$, is given by the following equation :

$$
\frac{C_{M}-C_{P}}{C_{B}-C_{P}}=\exp \left(\frac{J_{V}}{k}\right)
$$

Eq. 3 can be transformed to give an observed rejection, Robs, defined as $\left(\mathrm{C}_{B}-\mathrm{C}_{P}\right) / \mathrm{C}_{B}$, as

$$
\ln \left(\frac{1-R_{o b s}}{R_{o b s}}\right)=\ln \left(\frac{1-R}{R}\right)+\frac{J_{V}}{k}
$$

In general, the mass transfer coefficient, $\mathrm{k}$, depends on the feed flow velocity, $u$, as

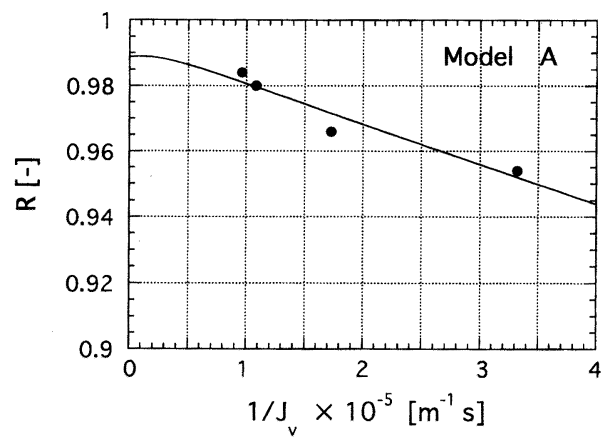

Fig. $2 \mathrm{R}$ vs $1 / \mathrm{J}_{V}$

shown in the next relationship :

$$
k \propto u^{a}
$$

Usually a is 0.875 for the spiral-type element ${ }^{9)}$.

$\mathrm{R}$ is determined by plotting the left term of Eq. 4 against $\mathrm{J}_{V} / \mathrm{u}^{a}$ and extrapolating $\mathrm{J}_{V} / \mathrm{u}^{a}$ to 0 . The $\mathrm{k}$ is then determined at each $\mathrm{u}$ from Eq. 4. An example of this plot is shown in Fig. 1.

The transport coefficients, $\mathrm{P}$ and $\sigma$, can then be determined by plotting the $\mathrm{R}$ obtained at different pressures against $1 / \mathrm{J}_{V}$ and curve- fitting to Eqs. 1 and 2. An example of this plot is shown in Fig. 2. From results thus obtained, the values of the reflection coefficient of all ions are found to be very close to 1 . In this case, only $P$ can be used to estimate $R$ from the next equation, which is obtained from Eq. $1^{10)}$.

$$
R=\frac{J_{V}}{J_{V}+P / \sigma} \approx \frac{J_{V}}{J_{V}+P}
$$

In the above calculation, $\mathrm{C}_{B}$ values, used to calculate Robs, are average values of ions in the inlet and the outlet feed water. When the feed water velocity is changed, also the recovery ratio of the feed water in the element also changes, which results in the outlet water concentration change. This affects 


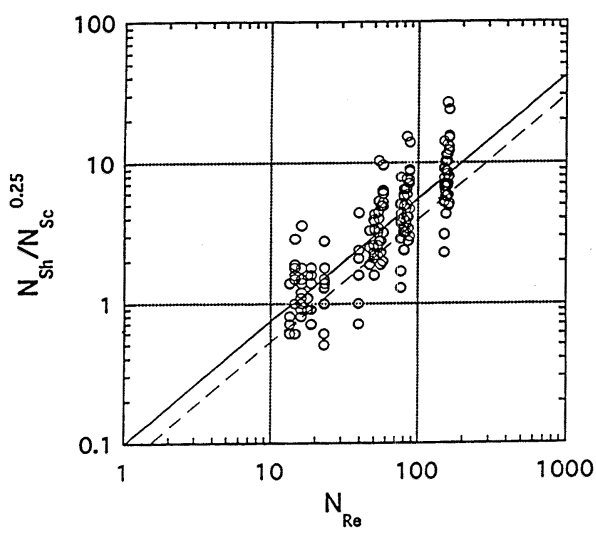

Fig. 3 Correlation of mass transfer coefficient.

the permeate ion concentration.

\section{2 Mass transfer coefficient}

Mass transfer coefficients previously obtained are transformed to Sherwood Number and correlated with Reynolds and Schmidt Numbers. The values of the diffusion coefficient of each ion are taken from the Handbook of Chemistry ${ }^{11}$. The results are shown in Fig. 3, where it is seen that the best fitted solid line shows a similar relationship to the dotted line, which follows the next equation reported earlier for the spiral-wound type module ${ }^{9)}$.

$$
N_{S h}=0.065 \cdot / N_{R e} e^{0.875} N_{S c} 0.25
$$

\section{3 Correlation of ion permeability}

Ion permeabilities through the membrane are plotted against ion diffusion coefficients in water and shown in Fig. 4. The results show that there is a definite correlation between them, although the data are rather scattered. The basic assumptions made in this analysis are that each ion permeates independently and, at the same time, the membrane charge does not affect the permeation

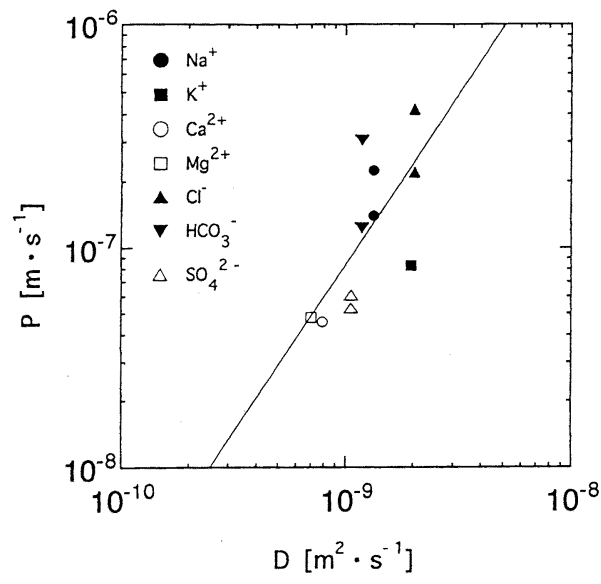

Fig. 4 Relation between $\mathrm{P}$ and ion diffusion coefficient in water.

of the ions. Therefore the results shown in Fig. 4 need further verification.

\section{4 Effect of osmotic pressure on flux}

The TDS values of each brackish water are usually several hundred $\mathrm{mg} / l$ and their osmotic pressure is not so high as to affect fluxes. However, under high-recovery or low-pressure operations, the osmotic pressure can affect flux. In this paper, the os $^{-}$ motic pressure of each brackish water is $\mathrm{de}^{-}$ termined from experimental data and compared with the calculated results. The volume flux is given by the next equation.

$$
J_{V}=L_{P}(\Delta P-\Delta \pi) \approx L_{P}\left(\Delta P-\pi\left(\sum i C_{M}\right)\right)
$$

where $\pi\left(\sum_{i} C_{M}\right)$ is the total ion concentration at a membrane surface, which is calculated from the following equation.

$$
\pi\left(\sum i C_{M}\right)=R T\left(\sum i C_{B}\right) \cdot \exp \left(\frac{J_{V}}{k_{i}}\right)
$$

From experimental data, the osmotic pressure is calculated by the next equation. 


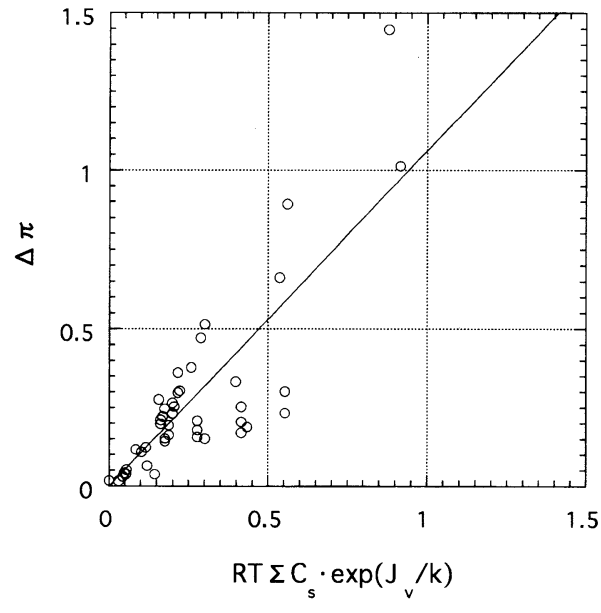

Fig. 5 Comparison between calculated and measured osmotic pressure.

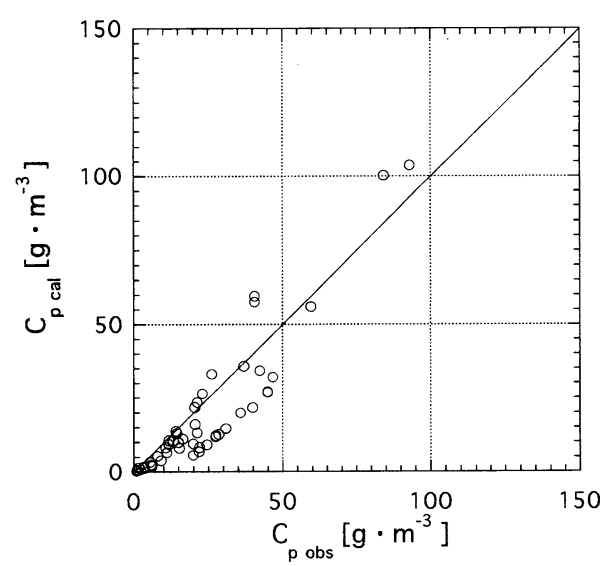

Fig. 7 Comparison between calculated and measured $\mathrm{Na}^{+}$ion concentrations in permeates of all blackish water tested.

$$
\pi\left(\sum i C_{M}\right)=\Delta P-\frac{J_{V}}{L_{P}}
$$

A comparison of both results is shown in Fig. 5, where it is seen that they generally coincide. Fluxes calculated using Eqs. 7 and 8 are given in Fig. 6, where the coincidence is shown to be good.

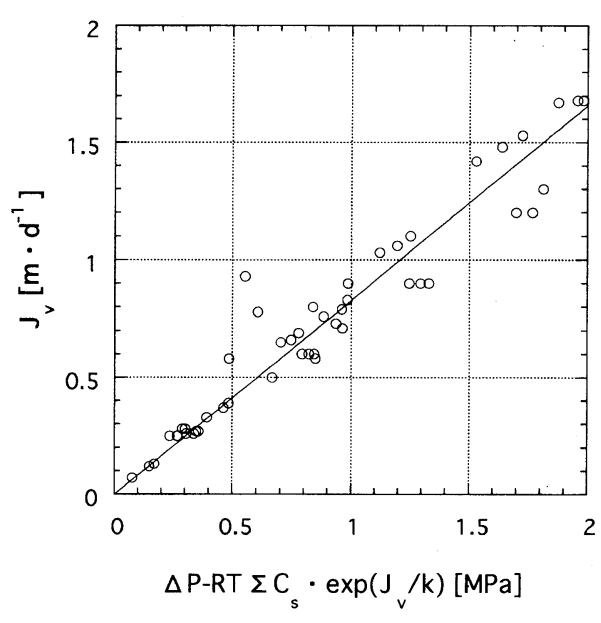

Fig. 6 Comparison between calculated and measured flux.

\section{5 Estimation of ion concentrations in the permeate}

Each ion concentration in the permeate can be obtained using the next equation, which is derived from Eqs. 3 and 5.

$$
C_{P}=C_{B} \cdot \frac{P \cdot \exp \left(J_{V} / k\right)}{J_{V}+P \cdot \exp \left(J_{V} / k\right)}
$$

An example of the comparison between the experimental and calculated values of the $\mathrm{Na}^{+}$ion concentration in the permeates of all brackish water tested is shown in Fig. 7, where they demonstrate good coincidence. In this calculation, the $\mathrm{P}$ of $\mathrm{Na}^{+}$ion is $\mathrm{ob}^{-}$ tained from a solid line correlation shown in Fig. 4.

\section{6 Estimation of $\mathrm{pH}$ in the permeate}

A relationship between $\mathrm{HCO}_{3}{ }^{-}$and dissolved carbon dioxide concentration is given by the following equation :

$$
\log \left(\left[\mathrm{CO}_{2}\right] /\left[\mathrm{HCO}_{3}^{-}\right]\right)=\mathrm{pk}-\mathrm{pH}
$$

When the $\mathrm{HCO}_{3}{ }^{-}$concentration and $\mathrm{pH}$ are measured, the $\mathrm{CO}_{2}$ concentration can be cal- 


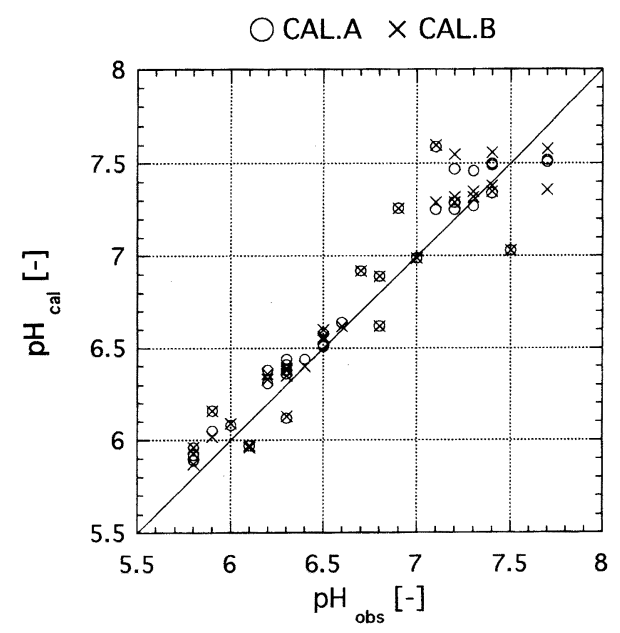

Fig. 8 Comparison between calculated and measured $\mathrm{pH}$ of permeate solutions.

culated. From the experimental data, it is found that the $\mathrm{CO}_{2}$ concentrations in the feed and the permeate are almost equal, and this shows that $\mathrm{CO}_{2}$ permeates through the membrane without rejection. Therefore, once the $\mathrm{HCO}_{3}{ }^{-}$concentration is known, the $\mathrm{pH}$ can be calculated using Eq. 11.

Following the previous procedure, the $\mathrm{pH}$ values are calculated by two methods, namely, using a measured $\mathrm{HCO}_{3}{ }^{-}$value in the permeate (CAL. A) and using an estimated $\mathrm{HCO}_{3}{ }^{-}$value explained in section 3.5 (CAL. B). They are compared with measured $\mathrm{pH}$ values in the permeates and are shown in Fig. 8, where it is seen that the coincidence is good. The results show that using this method, the $\mathrm{pH}$ can be estimated within an error of $\pm 0.5 \mathrm{pH}$.

\section{Conclusions}

Using a spiral element of a nanofiltration membrane (NTR-739HF), 8 kinds of underground brackish water are permeated by varying the operating pressure and the feed

\begin{tabular}{|llr|}
\hline \multicolumn{3}{|c|}{ Symbols } \\
$\mathrm{C}$ & ion concentration & {$\left[\mathrm{g} \cdot \mathrm{m}^{-3}\right]$} \\
$\mathrm{D}$ & diffusion coefficient & {$\left[\mathrm{m}^{2} \cdot \mathrm{s}^{-1}\right]$} \\
$\mathrm{d}_{h}$ & hydraulic diameter & {$[\mathrm{m}]$} \\
$\mathrm{i}$ & i coefficient of van't Hoff & {$[-]$} \\
$\mathrm{J}_{V}$ & volume flux & {$\left[\mathrm{m} \cdot \mathrm{s}^{-1}\right]$} \\
$\mathrm{k}$ & mass transfer coefficient & {$\left[\mathrm{m} \cdot \mathrm{s}^{-1}\right]$} \\
$\mathrm{L}_{P}$ & water permeability & {$\left[\mathrm{m} \cdot \mathrm{s}^{-1} \cdot \mathrm{Pa}^{-1}\right]$} \\
$\mathrm{N}_{R e}$ & Reynolds number, $\mathrm{d}_{h} \cdot \mathrm{u} / \nu$ & {$[-]$} \\
$\mathrm{N}_{S c}$ & Schmidt number, $\nu / \mathrm{D}$ & {$[-]$} \\
$\mathrm{N}_{S h}$ & Sherwood number, $\mathrm{k} \cdot \mathrm{d}_{h} / \mathrm{D}$ & {$[-]$} \\
$\mathrm{P}$ & ion permeability & {$\left[\mathrm{m} \cdot \mathrm{s}^{-1}\right]$} \\
$\mathrm{R}$ & true rejection & {$[-]$} \\
$\mathrm{R}_{o b s}$ observed rejection & {$[-]$} \\
$\mathrm{U}$ & feed flow velocity & {$\left[\mathrm{m} \cdot \mathrm{s}^{-1}\right]$} \\
$\Delta P$ & mechanical pressure difference & {$[\mathrm{Pa}]$} \\
$\Delta \pi$ & osmotic pressure difference & {$[\mathrm{Pa}]$} \\
$\nu$ & kinetic viscosity & {$\left[\mathrm{m}{ }^{2} \cdot \mathrm{s}^{-1}\right]$} \\
$\pi$ & osmotic pressure & {$[\mathrm{Pa}]$} \\
$\sigma$ & reflection coefficient & {$[-]$} \\
\hline
\end{tabular}

velocity. Eight items of the ion concentration in the permeate and flux are measured. The results obtained are analyzed using transport equations under the assumption that all ion components permeate through the membrane independently without the effects of mutual and ion-membrane interference.

First, the true rejection, $R$, and the mass transfer coefficients of each ion are determined using the velocity variation method. The $R$ values under different pressures are then curve-fitted to the Spiegler-Kedem equation to obtain the ion permeability, $\mathrm{P}$, and the reflection coefficient, $\sigma$. Because the latter value is very close to 1 for each ion, only $\mathrm{P}$ is used in the following analysis.

$P$ values thus obtained are found to have a definite relationship with the ion-diffusion 
coefficient in water. The mass transfer coefficients can be correlated to the similar form, which is reported previously for the spiraltype element.

Using all the obtained results, the flux can be estimated taking into consideration the osmotic pressure and ion concentrations. The $\mathrm{pH}$ values and ion concentrations in the permeate also coincided with these calculated data. Although the assumptions made in this paper have a certain limit in application, with this method it is simple to estimate the permeate water qualities.

\section{Literature cited}

1) T. D. Hodgson, Desalination, 8, 99-138 (1970)

2) R. Rangarajan, T. Matsuura, E. C. Goodhue and S. Sourirajan, Ind. Eng. Chem., Process Res. Dev., 17, 46 (1978)
3) R. Rangarajan, M. A. Mazid, T. Matsuura \& S. Sourirajan, Ind. Eng. Chem., Process Res. Dev., 24, 977 (1985)

4) T. Matsuura \& S. Sourirajan, "Theory and Practice of Reverse Osmosis", ed. by R. Bakish, IDA, pp.52-61 (1985)

5) M. Brusilovsky \& D. Hasson, Desalination, 71, 355 (1989)

6) T. Tsuru, S. Nakao \& S. Kimura, J. Chem. Eng., Japan, 24 (4), 511 (1991)

7) T. Tsuru, M. Urairi, S. Nakao \& S. Kimura, J. Chem. Eng., Japan, 24 (4), 518 (1991)

8) K. S. Spiegler \& O. Kedem, Desalination, 1, 311 (1966)

9) G. Schock \& A. Miquel, Desalination, 64, 339 (1987)

10) K. Fukunaga, M. Matsukata, K. Ueyama \& S. Kimura, MAKU (membrane), 22 (4), 211 (1997)

11) Handbook of Chemistry, ed. by The Chem. Soc. of Japan, Basic part, 4th ed. II-62 (1993)

（受付 1998 年 4 月 21 日 再投稿受付 6 月 17 日

掲載決定 7 月 1 日) 